\title{
Escárnio de corpos, Cyberbullying e corrupção do lúdico
}

\author{
Cynara Gonçales* \\ Giuliano Gomes Pimentel** \\ Beatriz Pereira***
}

\begin{abstract}
Resumo: Partimos do pressuposto que o bullying é um comportamento cruel, presente nas relações interpessoais, em que a pessoa mais forte converte os mais frágeis em objetos de diversão e prazer. Nós estudamos o bullying no ambiente virtual, a fim de tentar compreender sua ocorrência no tempo de lazer de alunos do ensino médio. Para tanto, realizamos pesquisa documental, selecionando três comunidades da rede social Orkut como material de análise. Analisamos as formas como os membros dessas comunidades praticam o cyberbullying sobre colegas da escola, sendo que o corpo é o foco principal das agressões. Entendemos que aulas de educação física tanto podem reproduzir quanto questionar esse tipo de assédio, ainda que este comportamento desviante de cyberbullying seja resultante do amplo contexto cultural e social dos adolescentes.
\end{abstract}

Palavras-chave: Bullying. Atividades de lazer. Imagem corporal.

\section{INTRODUÇão}

O bullying está presente nas relações interpessoais e se manifesta no comportamento cruel em que os mais fortes convertem os mais frágeis em objetos de diversão e prazer (FANTE, 2005). Cabe, nessa concepção, pensar que o poder é exercido de forma desigual e, portanto, o bullying é uma violência, mesmo que correntemente intangível, o que dificulta o exercício pedagógico

\footnotetext{
'Departamento de Educação Física, Universidade Estadual de Maringá, Maringá, PR, Brasil. E-mail: cynara_goncales@hotmail.com

"Departamento de Educação Física, Universidade Estadual de Maringá, Maringá, PR, Brasil. E-mail: giulianopimentel@uol.com.br

"*Instituto de Educação, Universidade do Minho, Portugal. E-mail: beatriz@iec.uminho.pt
} 
contra ele. Outro aspecto instigante é que formalmente ele pode ser visto como uma experiência lúdica para o agressor, bem como ser exercido para fora do ambiente escolar, onde é mais comum, ficaria travestido como atividade eleita no tempo disponível, isto é, bullying pode ser entendido como um divertimento (PIMENTEL, 2010).

Como o bullying dá prazer ao seu autor, um comportamento esporádico rapidamente se transforma em ação continuada, sistemática de agressão (bullying) na qual o sujeito que sofre essa agressão tem cada vez mais dificuldade em se defender. O bullying é uma forma continuada de agressão entre pares individual ou em grupo quando há intencionalidade, é repetida (OLWUES, 1993, SMITH; SARP 2004) e a criança ou jovem tem dificuldade em responder de forma assertiva de modo a sair da situação (PEREIRA, 2008).

Por se confundir com manifestações puramente jocosas, o bullying, a priori, seria compreendido próximo daquilo que Caillois (1994) denomina corrupção do lúdico, ou seja, quando o espírito do jogo excede seus limites e assume consequências danosas ao indivíduo e à sociedade. Em acréscimo, considerando bullying no tempo livre, teríamos uma dimensão patológica do lazer na perspectiva mefítica, isto é, comportamentos violentos exercidos contra pessoas ou lugares, como pontua Rojek (2005). Vindo neste sentido, em estudos empíricos de Pereira e Neto (1994; 1997), os comportamentos de bullying surgem como a face oculta do lazer. Tendo iniciado as suas pesquisas sobre as atividades de lazer das crianças, rapidamente se perceberam que o bullying tinha traçado linhas muito coloridas sobre o lazer das crianças.

O tom jocoso e lúbrico do bullying contribui para que não exista forte percepção do mesmo como um problema. O conhecimento dessa manifestação a partir de uma categoria (bullying: assédio contínuo, agressivo e desigual) teve início nos últimos 20 anos. Estes estudos iniciaram-se nos países nórdicos quando a natalidade era já muito baixa e a criança muito valorizada por ser em número

Movimento, Porto Alegre, v. 20, n. 3, p. 965-988, jul./set. de 2014. 
reduzido e todas as crianças tinham acesso a níveis elevados de educação (escolaridade obrigatória). Foi quando pela primeira vez se começaram a fazer estudos dando voz às crianças (PEREIRA, 2008).

Interessa em particular que o tempo livre na escola, particularmente o recreio, é identificado com forte associação à ocorrência dessa violência, mas, também, para sua reversão (CARVALHO; BARROS; PEREIRA, 2009). Para ilustrar, Pereira $(2006 ; 2008)$ implementou um programa de intervenção em escolas centrado nomeadamente na formação da comunidade escolar sobre o bullying, melhoramentos dos recreios e diversificação da oferta desportiva e cultural da escola e acompanhamento dos casos de bullying; Marques, Neto e Pereira (2001) e Marques et al (2005) desenvolveram um programa de intervenção centrado nos recreios escolares e em equipamentos lúdicos disponibilizados para as crianças, e supervisão, tendo revelado eficácia na sua prevenção. Por outro lado, a participação esportiva (federada ou escolar) não tem demonstrado efeito protetor significativo contra o bullying, o que pode estar relacionado com a cultura de treinadores em incentivar a hostilidade nesse ambiente (MELIN; PEREIRA, 2013).

Diante dessa problemática, considerando a contribuição da Educação Física, o presente trabalho se debruçou sobre o bullying, como uma forma de diversão à custa do acossamento de alguém em situação de vulnerabilidade (geralmente estudantes estereotipados como mais estudiosos, pobres, obesos, fracos, tímidos, esquisitos, religiosos ou feios) ou simplesmente o jovem que estava no lugar errado, na hora errada.

Já o cyberbullying é um tipo de bullying indireto ou direto (quando é identificado quem é a origem da agressão, como no caso de Facebook ou Orkut). Mesma sendo uma prática idêntica às outras, o recurso da tecnologia permite aumentar o anonimato do agressor e disseminar o mal-estar em grande escala.

Movimento, Porto Alegre, v. 20, n. 3, p. 965-988, jul./set. de 2014. 
Para o estudo empírico, considerando que a escola é um lugar privilegiado de educação para o lazer, optamos pelo estudo mais característico do bullying como lazer mefítico exercido livremente no tempo disponível. Isso significa que, fora do contexto da escola, alunos decidem, entre outras possibilidades de diversão, usar a internet para ridicularizar alguém e espalhar boatos sobre ele. Entre as diversas mídias nas quais se visualiza o cyberbullying, foram escolhidas comunidades do site de relacionamento Orkut. O objetivo foi analisar os modos pelos quais os membros dessas comunidades praticam bullying por meio do lazer virtual. Entre os modos, destacamos o escárnio, isto é, críticas e sátiras dirigidas a uma pessoa real, conhecida do grupo, sendo que aspectos corporais diferentes da estética normalizada são associados a desvios morais.

\section{Aspectos metodológicos}

Os dados foram obtidos por pesquisa documental, realizando coleta de materiais que não receberam ainda um tratamento analítico em sites não comerciais da internet e que se caracterizam como cyberbullying. $\mathrm{O}$ trabalho exploratório foi realizado nas páginas do Orkut, por este apresentar um material com maior incidência e denúncias de escárnio, gerando desde situações de cyberbullying a racismo.

Esse software foi desenvolvido por Orkut Büyükkökten, funcionário da Google, com a finalidade de estabelecer círculos sociais para relacionamento virtual. Desde janeiro de 2004 milhares de redes dos mais variados estilos foram criadas, permitindo que -mesmo à distância e sem nenhum contato prévio - várias pessoas pudessem se comunicar simultaneamente, em torno de temáticas de interesse e convidadas por intermédio de um terceiro (amigo em comum). Essa ferramenta de rede social foi especialmente popularizada no Brasil e sua utilização vem atendendo a diversas finalidades (COUTO; ROCHA, 2010).

De forma exploratória, recolhemos dez comunidades, todas brasileiras, para teste da matriz analítica. Foram selecionados

Movimento, Porto Alegre, v. 20, n. 3, p. 965-988, jul./set. de 2014. 
fóruns dos mais diferentes tipos no Orkut, ligados a momentos de lazer pouco convencionais, de modo a selecionar o tipo de comunidade mais orientado para o bullying. Na coleta exploratória foram analisadas as seguintes comunidades de lazer no Orkut: A Leigh B tem cara de cavalo; CLE - Centro de Lazer Errante; ODEIO GÓTICOS; As biscates Fuçam Meu Orkut; Vc vai na +feia e eu na outra!; AMO ouvir música ALTA; Eu odeio filme dublado; Preciso Morar na Praia; Eu só fumo Marlboro vermelho; Eu nunca terminei uma borracha.

A análise nessa fase permitiu selecionar palavras-chave, como "eu odeio...", que melhor se adequassem a direcionar a busca de comunidades com forte tendência ao cyberbullying. Foram selecionadas intencionalmente três comunidades para o estudo, tendo em comum a relação com meninas da escola e a caracterização corporal da vítima como foco principal do escárnio. O critério de triagem inicial foi que as comunidades fossem abertas. Como foram identificadas muitas, optamos pelas comunidades com maior quantidade de material escrito, de modo a permitir uma exegese mais segura dos textos. Como os modos de escárnios se reiteravam nas comunidades, por critério de saturação, foram analisadas as três com mais conteúdo.

A análise, na perspectiva da dialética hermenêutica, considerou os diferentes modos apresentados pelos agressores para atingir a vítima na comunidade. Nesse processo são descritos os escárnios à analogia de textos que necessitam de interpretação, a partir de variadas camadas de significado; o que nos faz recorrer a quem são os autores do texto e qual seu contexto de produção. As categorias de análise foram retiradas da recorrência dos escárnios e da diversificação dos modos de sua ocorrência. A partir daí realizamos análise de conteúdo, de forma a explicitar e compreender os modos de escárnio dos corpos no cyberbullying. Mas, como o bullying virtual retrata relações desiguais e multivariadas de poder, consideramos que um avanço ao nosso estudo seria submeter o material a uma análise na perspectiva foucaultina de genealogia.

Movimento, Porto Alegre, v. 20, n. 3, p. 965-988, jul./set. de 2014. 
A respeito dos "autores", muitos se tornam agressores no ambiente virtual pela necessidade de fazerem parte do grupo ou para não serem a próxima vítima, difamando então seus colegas. Esse processo pode ocorrer por meio das conversas entre os membros e pelos fóruns de discussão, nas enquetes referentes à vítima, deixadas pelos agressores, para que os membros pudessem votar. E até mesmo expondo uma ideia, iniciando um processo inverso, fazendo com que o dano seja causado pela vítima a si mesma.

Ao tomar as páginas de relacionamento como textos provenientes de documentos públicos, consideramos algumas limitações, entre as quais: a dificuldade em contextualizálas, a possibilidade de não veracidade, o acesso aos sites de relacionamentos ser circunscrito a convites de membros e, especialmente, a retirada de circulação de sites que promovem o cyberbullying de forma mais explícita, antes que se tenha o acesso aos mesmos.

Sobre os aspectos relacionados à privacidade, não há consenso entre os usuários. Academicamente, o uso desse material, que é público assim que é postado e acessado por outros, gera ainda insegurança. Ademais não há controle da identidade quando os usuários estão no ambiente virtual. $\mathrm{O}$ poder que o outro é capaz de exercer, assim como o uso e o grau de ocupação do espaço, quando relacionado ao pessoal, evidencia a necessidade em filtrar as informações (SCHWARTZ; COMPAGNA, 2006).

Devido à especificidade do estudo, não se recorreu ao contato direto com seres humanos e, consequentemente, não houve adoção de Termo de Consentimento Livre e Esclarecido. O projeto de pesquisa foi registrado como pesquisa documental e foi aprovado sob o n. CAAE 02695112.4.0000.0104. Assim, pelo uso de material de sites da internet ser ainda recente e o conteúdo poder revelar a identidade dos envolvidos no bullying, procedimentos éticos em pesquisa foram adotados, borrando as imagens e os endereços que pudessem comprometer o anonimato dos envolvidos.

Movimento, Porto Alegre, v. 20, n. 3, p. 965-988, jul./set. de 2014. 


\section{Resultados e discussão}

Em relação ao Orkut, Faustino e Oliveira (2008) entendem quatro maneiras como as mais usuais de expor uma pessoa: mensagens ofensivas no perfil da vítima; enviar-lhe mensagens pessoais; criar um falso perfil para a vítima ou criar uma comunidade. Segundo os autores, o cyberbullying nos sites de relacionamento tem o agravante de poder "ser visto por qualquer usuário e, assim, aumentar o pré-julgamento da vítima por aqueles que acessam esse conteúdo ofensivo" (FAUSTINO; OLIVEIRA, 2008, p. 187).

De fato, no Orkut foi possível identificar comunidades virtuais onde se pratica o bullying, como também foram encontradas aquelas voltadas para amparo às vítimas. $\mathrm{Na}$ era digital, apelidos pejorativos, manipulação de fotografias com efeitos negativos e exposição de fatos íntimos estão entre os achados que têm início nas salas de aulas e se alastram em comunidades no Orkut e conversas no MSN, além do cyberbullying mais temido: a exposição no Youtube.

A primeira comunidade selecionada foi criada em uma cidade no interior do estado de São Paulo em abril de 2007, e possui 35 membros desde que foi feita a análise. Essa comunidade não é do tipo moderada, é pública, ou seja, não é preciso que o dono autorize a entrada de um novo membro. Isso permite a um usuário entrar na comunidade, escrever insultos e então deixá-la em seguida, o que pode fazer com que sua identidade seja anônima frente aos membros do grupo ou qualquer outro usuário.

No caso, foram reunidas pessoas para ofender a vítima específica em conversas pelos fóruns. A figura abaixo ilustra a convocação à vingança contra o modo preconceituoso de se portar certa "menina cara de rã" (gíria que pode expressar feiura ou pessoa com olhos saltados e boca larga):

Movimento, Porto Alegre, v. 20, n. 3, p. 965-988, jul./set. de 2014. 
Figura 1 - Comunidade eu odeio essa menina cara de rã

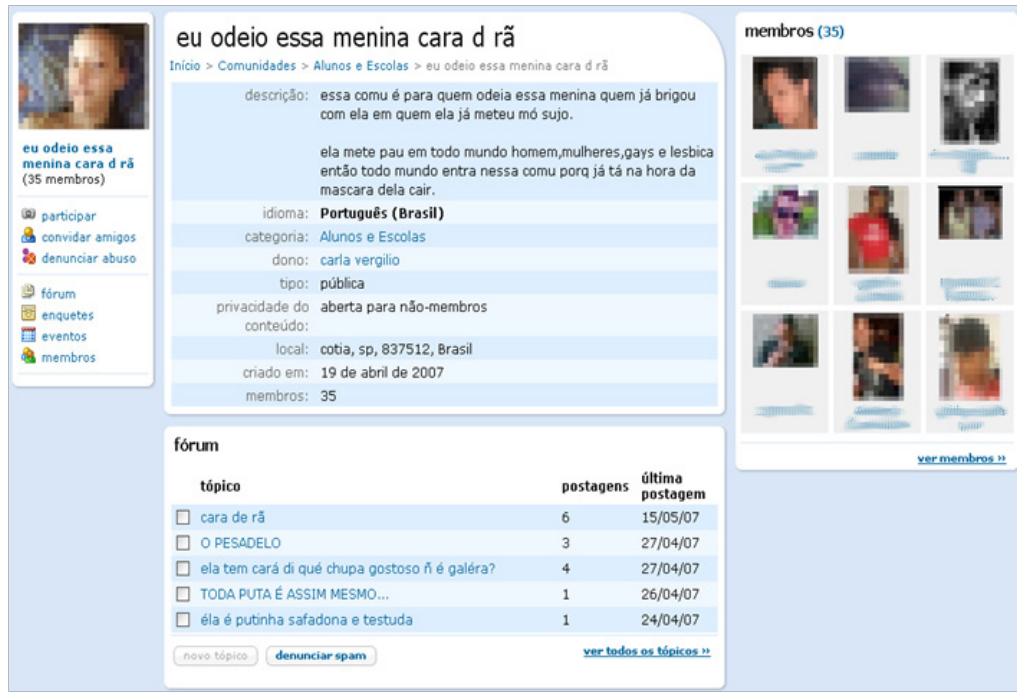

Fonte: Orkut

Outra característica é que esta comunidade não foi feita necessariamente para que os membros pudessem conversar entre eles sobre o fato de não gostarem da menina, mas para que ela também lesse os comentários que estão sendo feitos a seu respeito. Logo na descrição da comunidade fica claro que o objetivo é ofender e que de acordo com o perfil dos membros, a linguagem na descrição e fóruns de discussão, pode ser observado que são alunos do ensino médio.

A vítima é identificada na foto destinada ao espaço para inserção de uma imagem que identifica a comunidade, além do nome da cidade. No entanto, no espaço para a divulgação das comunidades relacionadas não existe nenhuma outra para compor a imagem da comunidade ofensiva, como visto em muitas comunidades.

O paradoxo do cyberbullying é que essa vítima, nesse caso, é tomada como uma agressora na escola. Os cyber-agressores conclamam aqueles insatisfeitos com o comportamento da colega 
para se manifestarem na comunidade. Isso é verossímil? Coerente com os estudos sobre bullying (FANTE, 2005), não é incomum que a mesma pessoa possa ser vítima no ambiente virtual e agressora na escola ou ainda se torne agressora após ser vítima.

Outra contradição é que, concomitante à suposta denúncia sobre os preconceitos da "menina cara de rã", a comunidade recorre, logo inicialmente, a uma caracterização física ao invés de moral. No fórum "cara de rã", se comentou:

ela realmente tem kara de rã,sua testa é de ferro, faz lembra a testa de um trem,além de ser despeita por perde os gts $\mathrm{p} /$ nós,rsssrssrsrsrsssrssrsrsrsrsrsrs....... (Comentário F1Taa).

gata porque tanto despeito, afinal nao temos culpa de vc ter nascido esse monstro que saiu direto da casa do espanto.. rsrsrs so tenho a lamentar por vc pois no seu caso nem plastica da jeito.. quer um conselho se mata... fuiiii (Comentário F1Tab).

Os comentários encontrados também não se situam na denúncia às agressões da colega de escola, mas no escárnio e na projeção -machista- de soluções. Basicamente, passam pela mecânica de que a feiura torna a vítima alguém desagradável socialmente, mas isso refletiria o desejo dela em receber atenção sexual. Nos Fóruns "Ela é putinha, safadona e testuda" e "O pesadelo", se infere que há combinação de agressão com calúnia e difamação.

iai vagabunda sua safada oque vc merece é levar um pal sua danada vadiazinha (Comentário F1Tfa)

Essa garota deve ser insuportável ,pois pela cara de R $\tilde{A}$ dela dar para perceber de imediato.Mas acho que ela parece mais como uma CUTIA NO CIL.Mas não tem jeito ,pois essa putinha deve ser de quinta categoria.Te toca, vai dar essa buceta escrota, pra ver se vc melhora essa cara de PEIXE MORTO , pois tá precisando.Há ,lembrei,mas quem vai querer esse bagulho?Ela tem várias características , como: PUTINHA, PÃO COM OVO , XEXELENTA , CARA DE DOIDA,

Movimento, Porto Alegre, v. 20, n. 3, p. 965-988, jul./set. de 2014. 
BUCHO DE CAVALO, CARA DE R , CUTIA NO CIL, X IRI DE VERME, PROFUNDA, E ETC. Agora ,pergunto: Quem se habilita para dar um grau nessa varejeira? (Comentário F1Tba).

O conteúdo das mensagens corrobora o mesmo estilo de agressões encontradas por Faustino e Oliveira (2008) em outras comunidades do Orkut. Coincidem: fala direcionada à vítima, que é mulher; difamação e calúnia; sugestão de suicídio; ofensas ligadas à sexualidade e ao corpo; ameaças; ironias e contradições nos argumentos; e agressão verbal e psicológica.

Dadas essas considerações, tomamos que o cyberbullying, na comunidade, se estrutura a partir dos seguintes argumentos: a) convocação para denegrir alguém sob o pretexto de que merece; b) esse merecimento se dá por comportamento antissocial; c) a suposta causa é a infeliz caracterização física da pessoa aliada à desqualificação sexual da mesma; d) a solução está nela realizar os instintos sexuais que lhe foram atribuídos pelos agressores; e) realização de catarse por meio das agressões verbais que dirigem ao objeto da revolta caracterizações físicas e psicológicas negativas; f) essa sistemática, ao se tornar pública, transforma os participantes em agressores, visto haver difamação contra a vítima, com previsíveis danos a ela.

A segunda comunidade foi criada em 13 de novembro de 2008, em Pelotas-RS, quando possuía 18 membros. O bullying escolar é evidente porque a descrição do autor (dono da comunidade) coloca o lugar onde, provavelmente, ambos estudam, identificando a garota, com foto e nome expostos, conforme a imagem abaixo confirma: 
Escárnio de corpos, Cyberbullying e ...

Figura 2 - Comunidade Odiamos a cara de CAVALO do jd

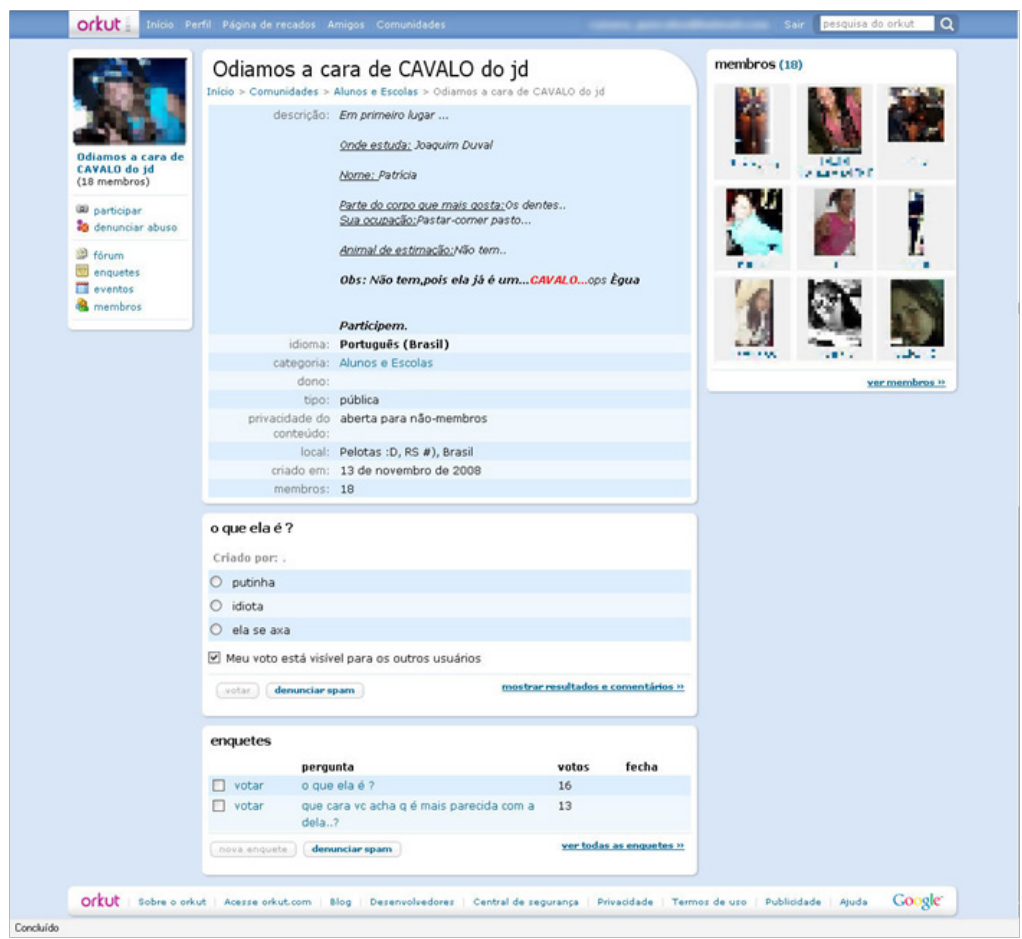

Fonte: Orkut

Comparando as comunidades analisadas, é sintomático que guardam a questão de gênero muito evidente, pois se destinam a ofender meninas e, não por menos, há desqualificação a partir do corpo, um capital simbólico fundamental para as relações sociais na adolescência, mas que, ao mesmo tempo, sofre transformações celeradas nesse período da vida. Conforme Azzarito e Solmon (2006), no ensino médio, os corpos sofrem qualificações (positivas ou depreciativas) conforme as expectativas atribuídas ao sujeito (filtrado por marcadores, como etnia e gênero) em torno da personalidade e do corpo (estatura, força, musculatura e aparência).

O que diferencia esta comunidade para a primeira citada, é que esta não possui comentários pejorativos nos fóruns de discussão. A

Movimento, Porto Alegre, v. 20, n. 3, p. 965-988, jul./set. de 2014. 
jovem é denegrida por meio de enquetes, nas quais os participantes votam sobre opções a respeito do self da vítima. Não há alternativas honrosas entre as opções: "putinha", "idiota" ou "ela se axa" para definir "o que ela é?".

Outro aspecto interessante é o apelo a marcadores faciais para estereotipagem. Se na outra comunidade a vítima é "cara de rã", nesta seria a "cara de cavalo" do colégio, cujas iniciais são JD. Além do curioso regionalismo no qual a "rã" é caracterizada numa cidade de várzea e a "cavalo" em uma região marcada pela tradição pecuária, é fundamental aos agressores ridicularizar e animalizar a vítima. Esse mecanismo de reificação, além de favorecer o ambiente de covardia, facilitaria o entendimento corrente entre os agressores de que, no fundo, se divertem ao realizar a agressão. Motivada inicialmente por algum sentimento de vingança, a comunidade vai gradativamente tomando ares mefíticos para a prática do escárnio, até se banalizar.

$\mathrm{Na}$ internet, esse aspecto lúbrico é plenamente compatível com a produção de enquetes cuja origem remete ao imaginário dos grandes sistemas de entretenimento midiático (rádio, televisão e, agora, internet) como em programas de auditório. Contribui para isso a grande relevância da relação estabelecida entre o lazer e a mídia no cotidiano juvenil (HACK; PIRES, 2007). Enfim, a internet será somente um meio de propagação do maior número possível de práticas juvenis, dentre as quais o escárnio vai assumir lugar especial graças à possibilidade do anonimato e à agressão não ocorrer no confronto direto com a pessoa alvo da infâmia. Neste raciocínio, o cyberbullying é deslocado do campo da agressão catártica para uma variante jocosa do lazer. Em suma, a violência é justificada pelas características do agredido para, posteriormente, ser diluída como uma brincadeira. Em outros termos, os participantes sublimam a violência ao brincar de ofender.

Mais recentemente, acompanhando novas perspectivas da atualidade, Schwartz (2003) sugere a inserção do conteúdo virtual do lazer, em função dos avanços tecnológicos e das novas práticas

Movimento, Porto Alegre, v. 20, n. 3, p. 965-988, jul./set. de 2014. 
propiciadas pela adesão ao ambiente virtual. O ambiente virtual é associado ao contexto do lazer, especialmente por colocar à disposição desse campo a oferta de oportunidades para satisfação pessoal e a criação de expectativas e desejos.

Com base em estudo aplicado via internet, Schwartz e Compagna (2006) mostram que com a interação com o mundo virtual, os sujeitos podem adotar condutas diferentes, como obter informações variadas e promover relacionamentos, disponibilizando oportunidades para satisfação pessoal e criação de expectativas.

Ainda em relação ao ambiente virtual como tecnologia para o lazer, é notório que a internet colocou os corpos privados em um novo patamar de visibilidade. Isso tem intensificado, entre outros dois efeitos complementares: a hiper exposição da intimidade e o pornolazer. Quanto ao primeiro aspecto, ao pesquisar videografias de si no Youtube, Ribeiro (2012) concluiu que esse tipo de expressão pessoal no ciberespaço facilita que questões relativas à intimidade da pessoa sejam involuntariamente reveladas. Entre os aspectos dessa auto representação virtual, Pimentel (2010) chama atenção para a "sensualização" dos sujeitos, de modo que o lazer produzido nessas experiências de si carrega elementos sutis de apelo sexual. Assim, se manifesta um duplo movimento: de um lado temos o imperativo de nos fazermos atraentes no ciberespaço, e do outro, no cyberbullying, os agressores se valem de conotações sexuais para o escárnio de corpos (vide comunidade "eu odeio essa menina cara de rã’).

A esse respeito, Rojek (2005, p. 186) mostra o aspecto negativo do lazer virtual em que as formas de lazer estão posicionadas na cultura como espaços em que o indivíduo reforça valores sociais fundamentais. Contudo, o tempo de lazer envolve o relaxamento dessas regras e regulamentações. Nesse sentido, essas práticas de lazer são compatíveis com o relaxamento que envolve a separação do indivíduo da sociedade e da cristalização de condutas antissociais. Existem formas e práticas de lazer destinadas tanto a prejudicar a si

Movimento, Porto Alegre, v. 20, n. 3, p. 965-988, jul./set. de 2014. 
como aos outros, o que justificaria os comportamentos individuais dos outros serem estereotipadas como negativos. Essas práticas se baseiam no compromisso violento contra o próximo e podem tanto se dissipar quanto alimentar o comportamento destrutivo no lazer.

Por fim, a última comunidade se destina mais explicitamente a zombar da menina considerada "a mais feia da escola". Esse foi o mote de cyberbullying mais encontrado na fase exploratória, quando as comunidades foram selecionadas, de tal forma a se inferir que ser bonita é um imperativo na sociabilidade escolar, sob os custos da execração pública e virtual àquelas mais suscetíveis a essa violência. No texto de descrição da comunidade, a justificativa é alçar a jovem ao "livro dos recordes" como a "Amina Mais Feia Do Mundo". Não há argumentos para tal, embora os apelidos atribuídos à jovem "Estrogonofe_Zoin _Baleia Terrestre" remetam a particularidades como obesidade e deficiência ocular.

A comunidade foi criada em 24 de junho de 2009 na cidade de São Paulo, e possui vinte membros desde que foi feita a análise. Essa comunidade como todas as outras citadas, é pública, ou seja, não é preciso que o dono autorize a entrada de um novo membro, permitindo a qualquer usuário entrar na comunidade, e responder às enquetes disponíveis (Figura 3).

Ao contrário da primeira comunidade, não há exaltação do ódio, o que reflete em respostas curtas e agressões menos virulentas. Porém, não deixa de ser inquietante observar como as perguntas da enquete se irmanam em torno da justificação para a feiura. Elas perfazem um caminho que nasce dos atributos inatos até se assentarem na confirmação moral desse atributo. Na questão "Porque vcs acham ela a mais feia da escola??", as respostas se dirigem à dimensão congênita: "Pq ela eh Feia de nascencia"; "Pq ela ja nasceu feia" ou "ela sempre foi feia". Em complemento, outra pergunta como "pq os ocolos dela esta quebrado?", remete à questão dos aspectos reforçadores da condição natural, uma vez que, alertando o olhar dos participantes para uma situação desfavorável, se situa a condição econômica como componente

Movimento, Porto Alegre, v. 20, n. 3, p. 965-988, jul./set. de 2014. 
perpetuador da feiúra. Ainda se pode fazer juízo de culpabilização da vítima, ridicularizando sua tentativa de contornar os óculos danificados, conforme uma das respostas: "affê o ocolos dela ta colado com fita adesiva kkk". Somando-se à descrição da jovem como sendo gorda, isso nos leva a inferir pelo reforço da interpretação moralizadora sobre os obesos como sendo pessoas desleixadas e, portanto, antíteses da beleza.

Assim, embora rudimentares, as falas são capazes de produzir sentidos dado estarem ancoradas em representações sociais de saúde e beleza. Logo, elas se constituem em agressão, mesmo que, pela via virtual, as consequências psicológicas à vítima geralmente não estejam sujeitas ao conhecimento da comunidade. Até porque os agressores, ao contrário do bullying presencial ou físico (mais comum entre homens), não presenciam os efeitos de seu assédio. (FAUSTINO; OLIVEIRA, 2008).

Figura 3 - Comunidade Amina Mais Feia Da ESCOLA.!

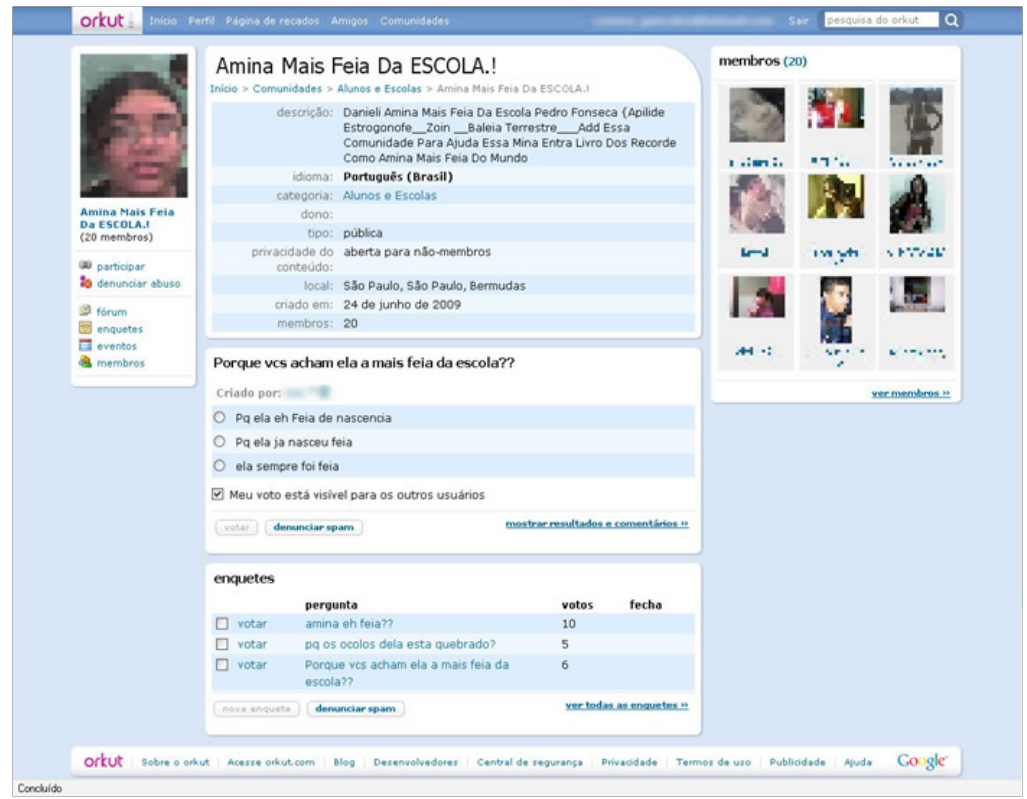

Movimento, Porto Alegre, v. 20, n. 3, p. 965-988, jul./set. de 2014. 
Conforme a imagem acima, entre as perguntas, há a solicitação em concordar (ou não) com a afirmação do site, colher as justificativas e identificar aspectos risíveis na imagem da jovem. Interessante que desde as perguntas (amina eh feia??) até as respostas (tadinha dexa ela se feia; sem duvida; Sin; concertezaa; claroo), é paradoxal notar uma comunidade na categoria "Escolas e alunos" fazer uso de uma outra linguagem que não é aquela (a norma culta) oficialmente ensinada na escola. Talvez o desejo de subversão se manifeste na escrita, embora apenas se crie uma nova codificação, dentro de um padrão mais alternativo. Enfim, no jogo de chiste cabem outras normas e é necessário dominá-las para fazer parte do grupo.

A respeito do coletivismo no cyberbullying, nessa comunidade, as enquetes foram feitas por outra pessoa (outro membro da comunidade), não por aquele que realmente fez a comunidade, o responsável. Esse aspecto é exemplar para situar que a vítima é perseguida de forma grupal (ou mefítica, conforme Rojek), e não necessariamente por um agressor isolado. Essa dimensão gregária do chiste é significativa tanto para isolar a vítima quanto para mover as relações lúbricas da sociabilidade mefítica. Nesse movimento, o que era para se tornar uma agressão passível de estranhamento e punição, ganha ares de diversão sádica. Em complemento, é plausível que muitos membros, às vezes, entrem pela necessidade de adequar-se à sociabilidade dominante, evitando se tornar a próxima vítima.

A esse respeito, Lopes Neto (2005) afirma que o uso de comportamentos agressivos contra os colegas é visto por muitos adolescentes como o melhor caminho para alcançarem a popularidade e, por isso, tornam-se autores de bullying, desencadeando essa premissa como regra de sobrevivência social. Se, como diz o ditado latino, o homem é o predador do homem, pois seria o único animal que mata por diversão, esse aspecto obscuro é canalizado nessas situações a ponto de, em fase posterior da vida escolar, virar rito tradicional nos trotes universitários e militares.

Por outro lado, embora essas ações expressem uma tendência

Movimento, Porto Alegre, v. 20, n. 3, p. 965-988, jul./set. de 2014. 
clara de organização entre opressores e oprimidos, típica da reprodução social, tal dinâmica, antes de ser algo naturalizado, é uma construção humana na linha do fenômeno em que oprimido hospeda o opressor de tanto ver imperar essa relação de sujeição (FREIRE, 2003). A própria adesão dos jovens a essas diversões mefíticas pode, não obstante o poder gregário, ser neutralizada diante do duplo reconhecimento, por um lado, da humanidade da vítima e, por outro lado, porque o chiste eletrônico não lhe é lúdico. A ilustrar essa análise, ainda na enquete amina eh feia??, chamou atenção a resposta de um dos participantes: "naun so participei da comu pq meus amigos pediu" (Comentário F3Tac). Fazendo uso dos mesmos códigos linguísticos e seguindo o preceito da sociabilidade juvenil em aderir a uma comunidade sugerida pelos amigos, ainda é possível ao sujeito dizer não, ou melhor, "naun" ao cyberbullying.

Já nos aproximando das considerações finais, o empoderamento do sujeito em não reproduzir essas práticas necessita também ser desenvolvido naqueles que são submetidos aos assédios, sejam eles virtuais, verbais ou físicos. Conforme Faustino e Oliveira (2008), o efeito do cyberbullying sobre as vítimas é indeterminado, pois costuma ser proporcional à representação que fazem de si mesmas. Na perspectiva de Paulo Freire (2003), empoderada é aquela pessoa (ou um grupo) capaz de agir com autonomia em prol das transformações.

Nesse caso, considerando que os resultados apontam para ataques baseados em estereótipos corporais, cabe perguntar qual a contribuição da Educação Física para o empoderamento dos alunos. Embora seja visto como canal privilegiado para ações, o problema maior dessa disciplina escolar é mais severo, pois as pedagogias tradicionais não seriam apenas inertes, mas também artífices dos padrões que balizam a posterior desqualificação e rejeição dos sujeitos cujos corpos são marginalizados (AZZARITO; SOLMON, 2006). Assim, nos parece precedente a mudança de paradigmas na Educação Física, de modelos disciplinadores para abordagens críticas, libertárias ou comunicativas. Afinal, não se trata de tomar ações pontuais de repressão ao bullying; por três motivos: esse fenômeno é

Movimento, Porto Alegre, v. 20, n. 3, p. 965-988, jul./set. de 2014. 
meramente a "ponta do iceberg da discriminação" alimentada pelos estereótipos, "as aulas de educação física reproduzem o contexto que os favorece" (OLIVEIRA; VOTRE, p. 173 e p. 194), e, se esse comportamento é determinado pelo contexto, a ação repressiva viria apenas a mascarar as causas, além servir de subterfúgio para que diferentes contestações estudantis sejam perseguidas.

Parece-nos que, no campo escolar, o desenvolvimento participativo e co-responsável de programas educativos deve ser a ação prioritária, pois visa fortalecer os sujeitos para enfrentar as adversidades, enquanto medidas punitivas e repressivas apenas surtem curto efeito. Assim, concordamos com Farenzena et al. (2011) para quem rotular e criminalizar as práticas mostrase reducionista "quando a natureza multifatorial do fenômeno estabelece a impossibilidade de uma resolução unilateral e pontual".

Portanto, mais que criar medidas punitivas e repressivas, que apenas canalizarão a pulsão mefítica para outras práticas, entendemos ser fundamental a instauração de outro modelo de sociedade, o que passa também pela mudança das práticas pedagógicas. A mesma escola que nutre o bullying é o lócus onde se propaga o domínio da racionalidade técnica, com a respectiva produção de corpos dóceis e produtivos, ao invés da constituição de sujeitos políticos emancipados. Nesse sentido, a Educação Física curricular que se propõe neutra é inerte, reproduzindo -de forma acrítica- os mecanismos de controle, perante os quais o bullying se projeta como uma reticente e incômoda derivação.

\section{Considerações finaIs}

Do rio que tudo arrasta se diz que é violento, mas ninguém diz violentas as margens que o comprimem (Bertold Brecht).

Para concluir o estudo, trazemos as seguintes considerações:

O conteúdo das mensagens analisadas privilegia características corporais como chamariz ao escárnio, embora aspectos morais

Movimento, Porto Alegre, v. 20, n. 3, p. 965-988, jul./set. de 2014. 
das vítimas também sejam evocados, especialmente nos insultos mais incisivos. Chama atenção que essas comunidades, por serem abertas, expõem a vítima. Logo, essa agressão ultrapassa a eventual necessidade de catarse e progride para a difamação.

Empiricamente, os achados possuem algumas recorrências. Merecem destaque que essas comunidades: 1) Estão situadas na categoria Orkut "Alunos e escolas". No caso das comunidades virtuais analisadas, estas são ramificações do bullying escolar; 2) Existe uma linguagem (errada diante das normas cultas) que os identifica como grupo ("tribo"); 3) Estão convivendo com a vítima, o que possibilita obtenção de foto digital da mesma; 4) Adotam características físicas como focos preferenciais da difamação; 5) Os integrantes exibem fotos deles (embora não esteja descartada a possibilidade de perfil falso - fake) e fazem os comentários em uma comunidade de acesso público, o que denota, naquele momento, a legitimidade nativa dada a essa prática (ou a confiança na impunidade); 6) A chacota catártica se torna prazerosa e gregária, podendo agravar para um quadro de divertimento sádico, embora nem todos convidados se manifestem assim.

Ao tratar o bullying como prática social não se faz sua apologia, mas o problematiza como ação concreta, sem viés moralista. É que, em momentos de lazer, o agressor ocupa seu tempo livre para manifestar sua agressividade, repúdio ou intolerância contra um particular ou determinado estereótipo de pessoas por meio da internet. Mas esse não é um comportamento desviante individual, o que nos levou a inferir pela sua caracterização como um lazer mefítico, ou seja, uma diversão disfuncional exercida em grupo, com traços insofismáveis de violência.

Em geral, esse comportamento é atribuído às gangues (como o caso de pichadores), denotando uma ação organizada para atingir uma atividade lúdica, socialmente mal-vista. Portanto, em sua complexidade, essas atividades se fazem às escondidas, mas no esforço para seu resultado ser visível a todos. Como o bullying é um fenômeno tardiamente classificado como inadequado na

Movimento, Porto Alegre, v. 20, n. 3, p. 965-988, jul./set. de 2014. 
sociedade, ainda foi possível notá-lo empiricamente no ínterim entre seus a(u)tores praticarem-no publicamente no meio virtual e o fazerem como algo desviante, underground.

Embora haja perfis preferenciais para esse chiste, o cyberbullying amplia os riscos de alguém cambiar entre vítima, agressor ou testemunha ou ser vítima/agressor. Em decorrência disso, essa atividade está inserida em um conjunto difuso de poderes, no qual os indivíduos organizados e empoderados estariam, em tese, mais aptos à resistência.

Em face disso, o conhecimento das consequências de abuso pelo bullying e/ou pelo cyberbullying é complexo e de difícil resolução. As generalizações não são bem-vindas, sendo fundamental, pois, que a escola trate desse problema tal como ele é, com seus paradoxos e complexidade. Portanto, o trabalho educativo deve ser contínuo, prevalecer sobre o paradigma repressivo, e incitar mudanças estruturais na missão da escola. Como disciplina privilegiada para se sentir/pensar o lúdico, mas não a única, a Educação Física vem recebendo atenção nos programas anti-bullying, especialmente com trabalhos especiais no intervalo escolar. Essa iniciativa é, porém, insuficiente, meramente compensatória. A materialidade das comunidades analisadas nos aponta que padrões corporais enaltecidos nas vertentes hegemônicas da área são usados como referência para o chiste no cyberbullying. Como a Educação Física poderá se revelar educativa frente ao bullying se ambos estão (a)fundados nas mesmas bases ético-estéticas? Ao pensar no desdobramento desses achados no campo de intervenção, reiteramos as preocupações pertinentes à nossa comunidade profissional quanto aos desvios que reificadas normas corporais podem reforçar, como inferimos aqui em relação ao escárnio de corpos no cyberbullying.

Como limites do estudo, foram selecionados apenas casos de comunidades no Orkut que se baseiam nas formas de agressões através do cyberbullying, que retratam a violência que começa na escola. Ainda situamos a necessidade em ampliar as categorias de

Movimento, Porto Alegre, v. 20, n. 3, p. 965-988, jul./set. de 2014. 
análise, bem como a realização de estudos de campo a partir da visão dos atores envolvidos, comparando-as com as representações identificadas nos documentos on-line (a fonte delimitada deste estudo). No plano teórico, também cabe situar que fugiu ao escopo da análise a, reflexão sobre as violências produzidas na sociedade e na escola e como elas afetam a objetivação do bullying como atividade no tempo livre. Nessa linha, também é importante aumentar a reflexão sobre o bullying e a Educação Física como coadjuvantes de uma subjugação maior, travestida não só como controle, mas também como sedução. Outro ponto merecedor de debates é o papel das diferentes disciplinas curriculares, na escola, quanto ao imperioso movimento de democratização do acesso a computadores e internet. Esse debate, entretanto, ainda está muito focado nos procedimentos técnicos, carecendo de abordar as dimensões políticas e éticas - o que reverberaria nas práticas de cyberbullying. 
Mocks the bodies, cyberbullying and corruption of the ludic Abstract: In this study we aim to define what is meant by bullying a cruel behavior, intrinsic in interpersonal relationships, in which the strongest person converts the most fragile in objects of fun and enjoyment. We have researched the cyberbullying in order to try to understand the practice of this type of crime in a virtual environment at the leisure-time of students. The study presented below was based on the documental research, supported by a critical review of the literature. Among the various ways in which occurs the cyberbullying, were selected communities in the social networking site Orkut. In the analysis, we have discussed the ways in which members of these communities practice in their free time the cyberbullying. The body is the major focus of the aggressions, whereby physical education classes reproduce the context that favors them, but it may also help in the cause and awareness about the problem. However, this deviant behavior in cyberbullying is part of whole cultural and social contexts of individuals.

Keywords: Bullying. Leisure activities. Body image.

Escarnio de cuerpos, cyberbullying y corrupción de la
lúdica
Resumen: En este estudio nos proponemos definir el acoso
(bullying) como una conducta cruel, intrínseca en las relaciones
interpersonales, en el que la persona más fuerte convierte
el más frágil de los objetos de diversión y escarnio. También
definimos lo que es el ciberespacio y el entretenimiento virtual y,
a continuación, describimos el acoso cibernético, a fin de tratar
de entender la práctica de este tipo de delitos en un entorno
virtual en el tiempo de ocio de los estudiantes. El estudio
que se presenta a continuación se basa en la investigación
documental, con el apoyo de una revisión crítica de la literatura.
Si uno accede a sitios relevantes de Internet, la identificación
de artículos y textos sobre el tema recientes. Entre las
diversas formas en que se produce el acoso cibernético había
comunidades seleccionadas en la red social Orkut. En el análisis,
hemos hablado de las formas en que los miembros de estas
comunidades de práctica en su tiempo libre el cyberbullying. Sin
embargo, estos comportamientos de riesgo, la intimidación, es
parte de todo un contexto cultural y social de los individuos, por
lo que las clases de educación física reproducen el contexto
que les favorece, y también puede ayudar en la causa y la
concienciación del problema.
Palabras clave: Acoso escolar. Actividades recreativas. Imagen
corporal.

Movimento, Porto Alegre, v. 20, n. 3, p. 965-988, jul./set. de 2014. 


\section{REFERÊNCIAS}

AZZARITO, L.; SOLMON, M. A. A Poststructural analysis of high school students' gendered and racialized bodily meanings. Journal of teaching in Physical Education, Champaign-U.S., v. 25, n. 1, p. 75-98, 2006.

CAILLOIS, R. Los juegos y los hombres: la máscara y el vértigo. México, D. F.: Fondo de Cultura Econômica, 1994.

CARVALHO, J. E; BARROS, P. C.; PEREIRA, B. O lúdico como uma possibilidade de intervenção ao bullying e formação da criança na escola. In: CONGRESSO NACIONAL DE EDUCAÇÃO, 9., 2009, Curitiba. Anais... Curitiba, 2009.

COUTO, E. S.; ROCHA, T. B. (Org.). A vida no Orkut: narrativas e aprendizagens nas redes sociais. Salvador: EdUFBA, 2010.

FAUSTINO, R.; OLIVEIRA T. M. O cyberbullying no Orkut: a agressão pela linguagem. Língua, literatura e ensino, Campinas, v. 3, p. 183-193, 2008.

FANTE, C. Fenômeno bullying: como prevenir a violência nas escolas e educar para paz. Campinas: Verus, 2005.

FARENZENA, R.; COSTA, P.; PEREIRA, V.; PEREIRA, B. Bullying escolar: descrição de um projeto de intervenção. In: VII SEMINÁRIO INTERNACIONAL DE EDUCAÇÃO FÍSICA, LAZER E SAÚDE, 7, Braga. Anais... Braga, 2011

FREIRE, Paulo. Pedagogia do oprimido. 36. ed. Rio de Janeiro: Paz e Terra, 2003.

HACK, C.; PIRES, G. L. Lazer e mídia no cotidiano das culturas juvenis. Licere, Belo Horizonte, v. 10, n. 1, p. 1-22, 2007.

LOPES NETO, A. A. Bullying: comportamento agressivo entre estudantes. Jornal de Pediatria, Rio de Janeiro, v. 81, n. 5, supl., p. s164-s172, 2005.

MARQUES, A. R.; NETO, C.; PEREIRA, B. O. Changes in school playground to reduce aggressive behavior. In: MARTINEZ, M. (Ed.). Prevention and control of aggression and the impact on its victims. New York: Kluwer Academic, 2001. p. 137-145.

MARQUES, A. R.; NETO, C.; PEREIRA, B.; ANGULO, J. Bullying no contexto escolar: jogo e estratégias de intervenção. Cinergias, Santa Cruz do Sul, v. 6, n. 1, p. 81-95, 2005.

MELIM, F. M. O.; PEREIRA, B. O. Prática desportiva, um meio de prevenção do bullying na escola? Movimento, Porto Alegre, v. 19, n. 2, p. 55-77, abr./jun. 2013.

OLIVEIRA, F. F.; VOTRE, S. J. Bullying nas aulas de educação física. Movimento, Porto Alegre, v.12, n. 2, p. 173-197, 2006.

OLWEUS, D. Bullying at school: what we know and what we can do. Oxford: Blackwell, 1993.

Movimento, Porto Alegre, v. 20, n. 3, p. 965-988, jul./set. de 2014. 
PEREIRA, B. O. Para uma escola sem violência. Estudo e prevenção das práticas agressivas entre crianças. 2. ed. Lisboa: Fundação Calouste Gulbenkian, Ministério da Ciência e Tecnologia (MCT), 2008.

PEREIRA, B. O. Prevenção da violência em contexto escolar: diagnóstico e programa de intervenção. In: SOUZA NETO, J. C.; NASCIMENTO, M. L. B. P. (Org.). Infância: violência, instituições e políticas públicas. São Paulo: Expressão e Arte, 2006. p. 43-51.

PEREIRA, B. O.; NETO, C. O tempo livre na infância e as práticas lúdicas realizadas e preferidas. Ludens, Lisboa, v. 14, n. 1, p. 35-41, 1994.

PEREIRA, B. O.; NETO, C. A infância e as práticas lúdicas. Estudo das actividades de tempos livres nas crianças dos 3 aos 10 anos. In: PINTO, M.; SARMENTO, M. (Org.). A infância: contextos e identidades. Braga: Centro de Estudos da Criança, 1997. p. 219-264.

PIMENTEL, G. G. A. Sobre os desvios no lazer: questões para se pensar a corrupção do lúdico. In: LARA, L. M. (Org.). Abordagens socioculturais em Educação Física. Maringá: EdUEM, 2010. p. 81-112.

RIBEIRO, D. C. C. As representações do eu na rede social Youtube: quando o íntimo atravessa os limites do público e do privado. Dissertação (Mestrado em Cognição e Linguagem) - Universidade Estadual do Norte Fluminense Darcy Ribeiro, Rio de Janeiro, 2012.

ROJEK, C. Leisure theory: principles and practice. [s.I.]: Palgrave Macmillan, 2005.

SCHWARTZ, G. M. O conteúdo virtual do lazer: Dumazedier. Licere, Belo Horizonte, v. 2, n. 6, p. 23-31, 2003.

SCHWARTZ, G. M.; COMPAGNA, J. Lazer e interação humana no ambiente virtual. Motriz, Rio Claro, v. 12, n. 2, p. 175-178, 2006.

SMITH, P. K.; SHARP, S. The problem of school bullying. In: SMITH, P. K.; SHARP, S. (Org.). School bullying: insights and perspectives. London a New York: Routledge, 1994.

Endereço para correspondência:

Av Colombo, 5790

Departamento de Educação Física

Universidade Estadual de Maringá

CEP 87020-900

Recebido em: 25.06.2013

Aprovado em: 01.05.2014

Movimento, Porto Alegre, v. 20, n. 3, p. 965-988, jul./set. de 2014. 